\title{
Collect and Store Solar Thermal Energy in Wall- Cladding System by Using Metal Foam
}

\author{
Ahmed Mohsin*, Mohammed H. Alhamdo, Basima Salman Khalaf \\ College of Engineering, Al-Mustansiriyah University, Iraq
}

Received September 2, 2019; Revised October 21, 2019; Accepted October 26, 2019

Copyright $\bigcirc 2019$ by authors, all rights reserved. Authors agree that this article remains permanently open access under the terms of the Creative Commons Attribution License 4.0 International License

\begin{abstract}
Theoretical and experimental investigations have been adopted to collect and store solar energy in exterior-wall cladding by using metal foam which incorporated with a phase-change material (PCM). Copper square duct was used to heat the air flow inside the duct. Various improvements have been investigated inside and outside the duct to increase the efficiency of heating. Analysis software has been used to simulate all models under investigation. Results show that there is a good agreement between experimental and numerical results and this agreement increases as air velocity increases. The average percentage error for air inside the duct at a velocity of air $1 \mathrm{~m} / \mathrm{s}, 3 \mathrm{~m} / \mathrm{s}$ and $5 \mathrm{~m} / \mathrm{s}$ is $8 \%, 16.5 \%$ and $5 \%$ respectively. A metal foam has been used to increase the thermal conductivity outside the duct. Also the results depict that the temperature gain for air velocity of 1,3 and $5 \mathrm{~m} / \mathrm{s}$ enhanced by about $8,8.4$ and $15.8 \%$, respectively. Metal foam has also been used outside the duct with both granular hollow sphere duct and vertical cylinders to increase the conduction effect. The enhancement in heat transfer for air velocity of 1,3 and $5 \mathrm{~m} / \mathrm{s}$ is found to be $29 \%$, $34 \%$ and $35.7 \%$ respectively for this case. Paraffin wax has been also used as a thermal storage media for enhancing the time of thermal discharge. The granular duct, with cylinders and foam, has been found as the best thermal response model (among all models under investigation). A new Nusselt number correlation equation has been developed for the best thermal response model that was found in this work.
\end{abstract}

Keywords Thermal Energy Storage, Metal Foam, Phase Change Material, Infrared Thermal Imaging, AnsysFluent

\section{Introduction}

Recently, most of researchers have been tried to find new ways for improving the heat transfer in several heat applications. Undoubtedly, there are many ways could be utilized to improve the heat transfer, one and of most important of these ways is the porous media. There are several types of porous materials, one of the most types that are widely used is metal foam in many applications such as cryogenics, combustion chambers, and compact of heat exchangers for the airborne of equipment and the air cooled condenser [1]. The characteristics of foam are cheap, light with low density, high strength and hardness. Generally metal foams are produced in 5, 10, 20 and 40 PPI size (where the PPI is pores per inch). The open-cell type is widely used due to several reasons, such as it has clear shapes, which lead to obtain data about the size and shape easily. It is used as a main part in many heat transfer devices, especially with the heat exchangers. Opens- celled metallic of foams are considered as one of the most promising materials to enhance the heat of transfer due to their high thermal conductivities, high the surface of area densities and high porosity. The phases change materials (PCMs) have become widely utilized as a heat storage median, thus became enticing for more investigations. The phase change materials have ability to store and hence enhancement the heat transfer significantly. Paraffin (wax) is one of the most popular organic heat storage (PCMs) for the commercial applications, it consists of a straight chain of hydrocarbons having the melting temperatures ranging between $23^{\circ} \mathrm{C}$ and $67^{\circ} \mathrm{C}$ [2].

Dukhan, N., et al. [3] conducted an experimental and theoretical study for thermal development in open-cells metal foam under constant wall heat flux. The results showed that the theoretical solution for local thermal non-equilibrium matched the experimental data very well (within a maximum difference of 4.6\%). Nawaz, K. [4] conducted a study in order to investigate coated metal foams for dehumidification. The selected model was studied to show the saturation time of the different models for dehydration and coating thickness. Metal foams coated with silica dryers have a higher thermal absorption capacity 
and a dampening rate per unit size for the same coating thickness.

An investigation for forced convection heat transfer of water-cooled in micro channel heat sinks with various structured metal foams has been studied experimentally and numerically by Shen et. al. [5]. Thermal resistance was found to increase by increasing the porosity of the metal foams. Furthermore, it was discovered that the foam contact are potential to increase the efficiency of performance. Alkilani et al. [6] carried out a study to the output of air temperatures prediction in the solar air heaters integrated with a phase change of materials. In this work, several parameters have been investigated such as the material used to change the phase is paraffin wax mixed with 0.5 aluminum powder to improve the performance. The results manifested that the addition of aluminum has reinforced the thermal conductivity by about $167 \%$ and revealed that the temperature of the outside air decreases gradually with the flow. Du, Y. and Y. Ding [7] investigated the charge / discharge rate of the latent heat thermal energies storage ( LHTES ) by embedding the metal foam in the phases change of materials (PCMs). The distribution and thermal conductivity were improved by 21 times due to the addition of paraffin to the vertebrates. The composite materials were enhanced by approximately
8 times and that was due to the embedding of $\mathrm{Al}$ foams with the paraffin material.

\section{Physical Model}

The current study investigated a solar collector and storage system by using compressed fluid (air) as a working fluid inside a smooth copper duct with dimensions of $(50 \times 25 \times 800) \mathrm{mm}^{3}$ and the other granular duct with a semi spheres $10 \mathrm{~mm}$ diameter that placed in $(150 \times 600 \times$ 60) $\mathrm{mm}^{3}$ copper insulated basin. Two types of copper cover both with dimension of $(70 \times 160) \mathrm{mm}^{2}$ and $0.5 \mathrm{~mm}$ thickness plate have been used. The first cover was smooth, while the second has vertical copper cylinders with $12 \mathrm{~mm}$ diameter and $40 \mathrm{~mm}$ length that extended inside the duct.

Ansys software has been used to simulate all models under investigation. The first model (base line case) considers a smooth duct and cover (SDSC model), as shown in Figure 1. The second model has been added the foam from both duct sides and cylinders (SDYF model), as shown in Figure 2. The third model has been added to foam with granular duct and cylinders (GDYF model), as shown in Figure 3, and finally the phase change material (wax) was added inside the storage basin (GDYFW model).

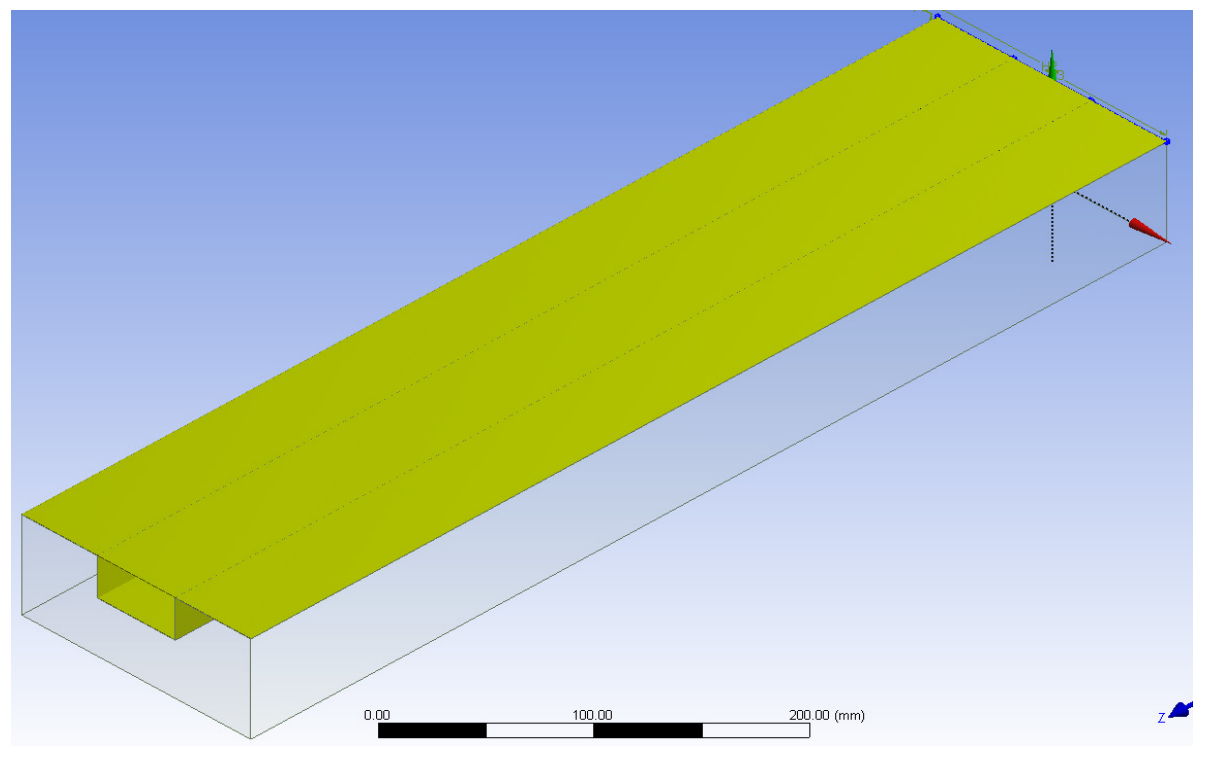

Figure 1. Geometry form of base line SDSC model 


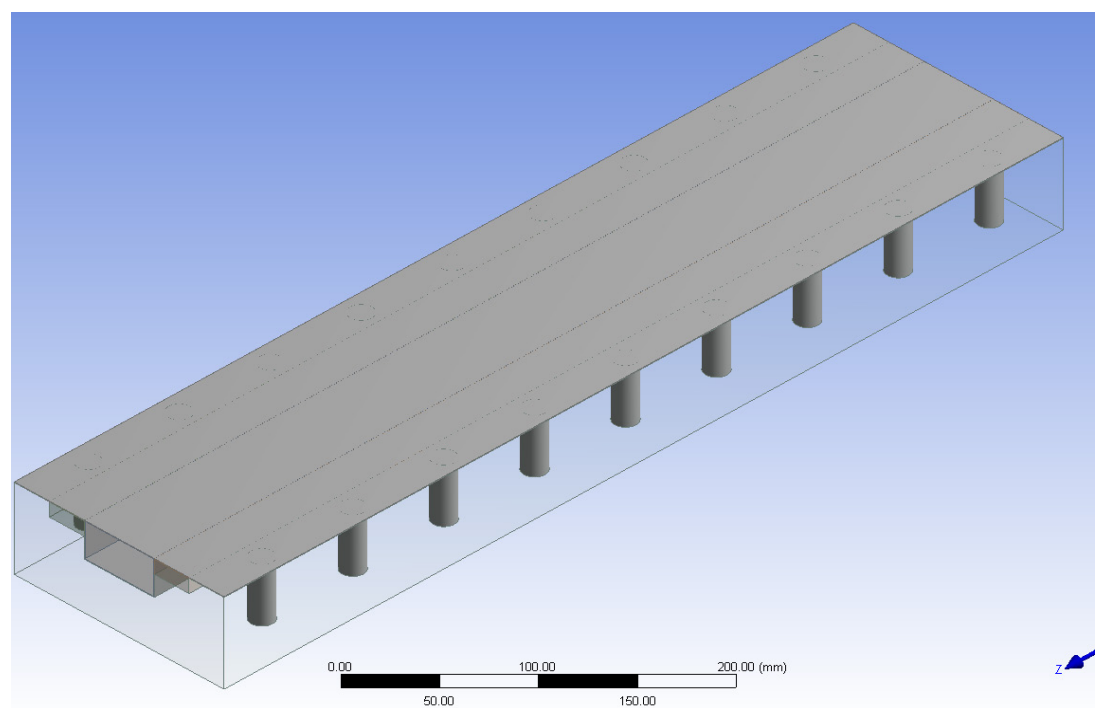

Figure 2. Geometry form of SDYF model

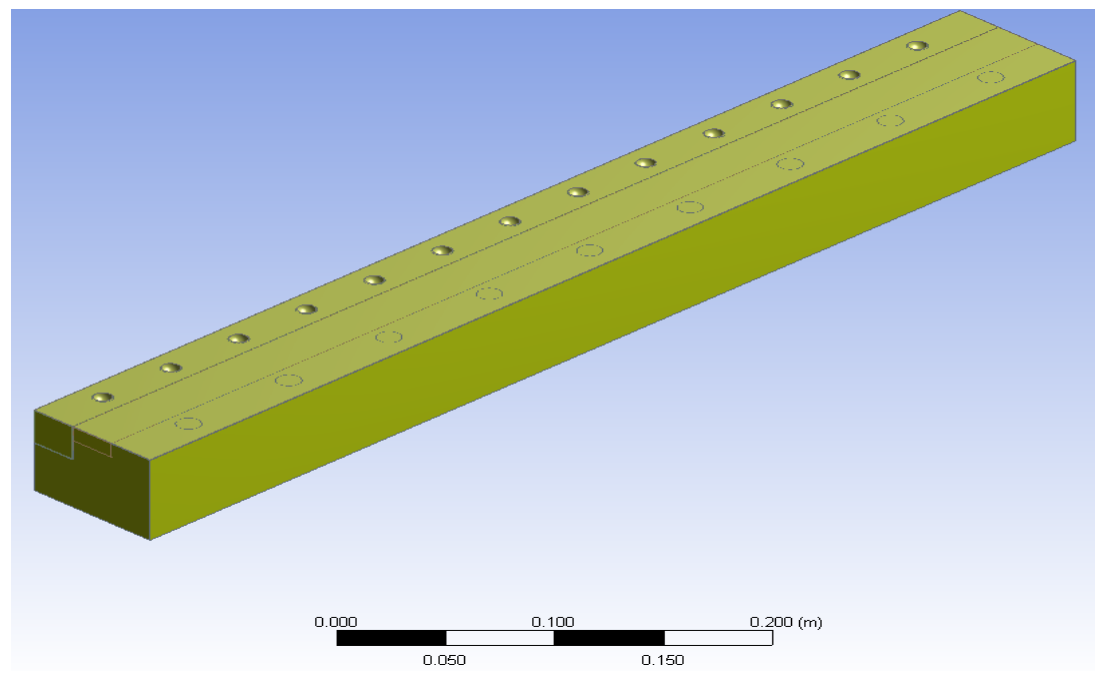

Figure 3. Geometry form of GDYF model

The multizone meshes have been generated for SDSC model and that gave a number of elements 3185185 with an element size of 0.003 , so there is no great variation in the output accuracy, as shown in figure 4

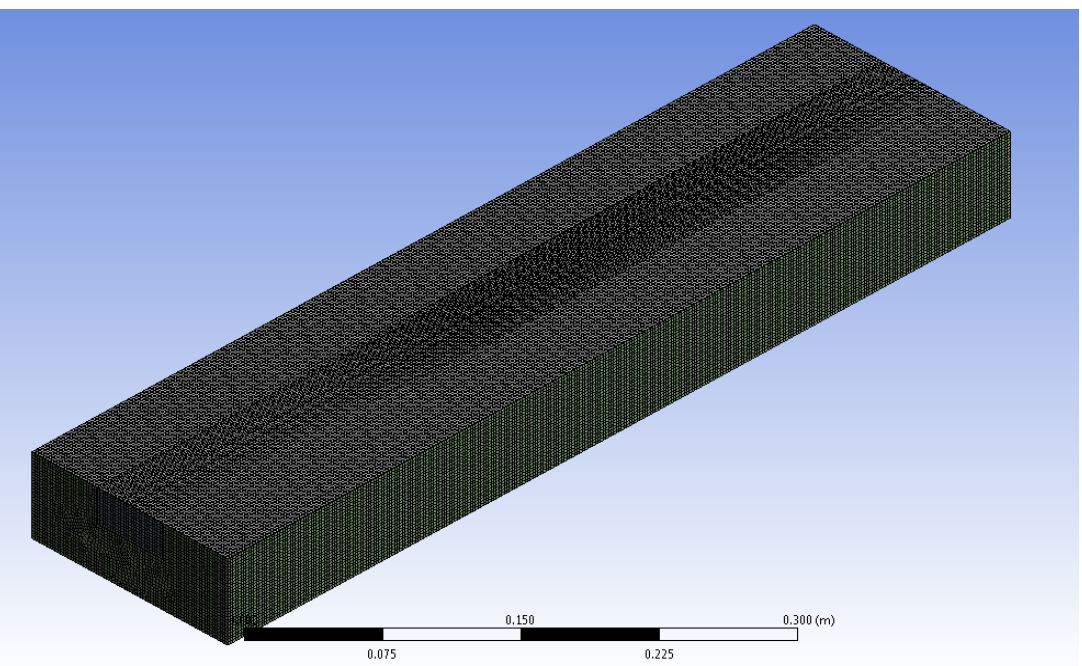

Figure 4. Mesh form of base line SDSC model 
The SDYF model contains metal foam and that makes an increase in the number of elements and the time interval to build the mesh of structure. Whereas, the elements were 3699674, as shown in Figure 5

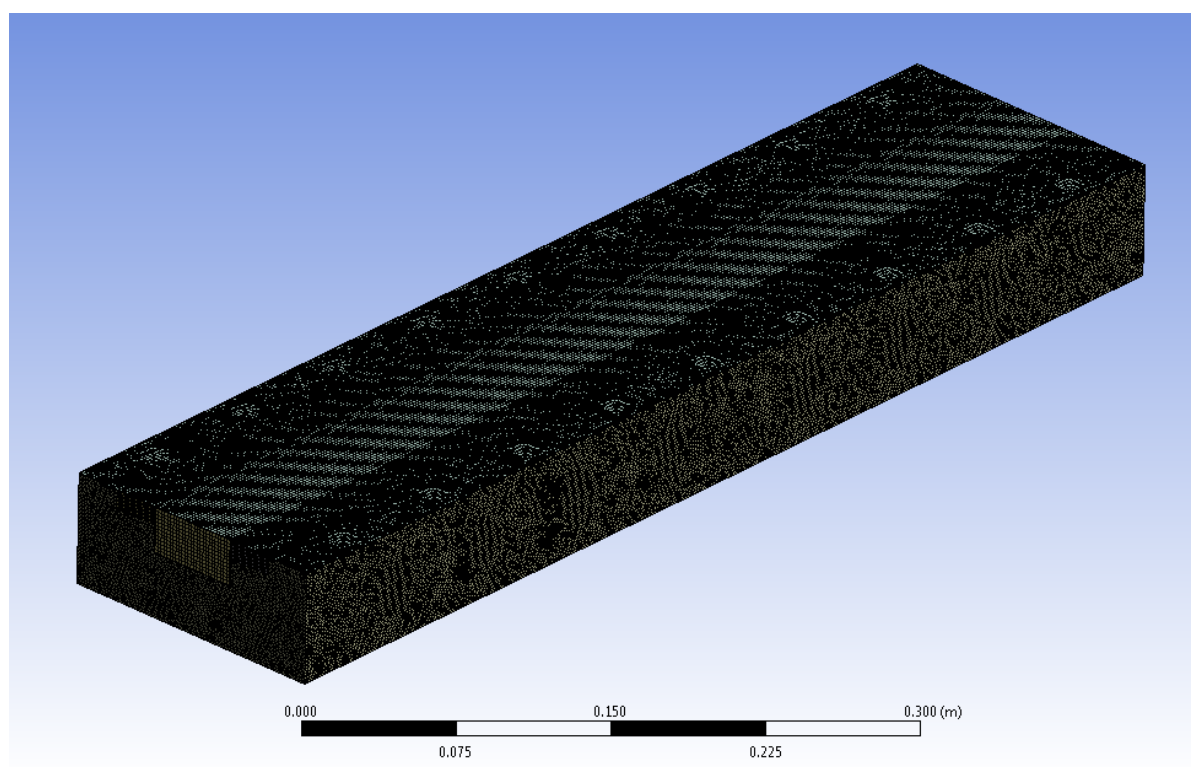

Figure 5. Mesh form of SDYF model

The foam effect was very clear in mesh structure for GDYF model. The granular effect increased the complication in mesh building in time and number of elements. The elements number was 7545744 and in the second attempt, it was 8620538. The time interval to build the mesh was taken more than 160 minutes.

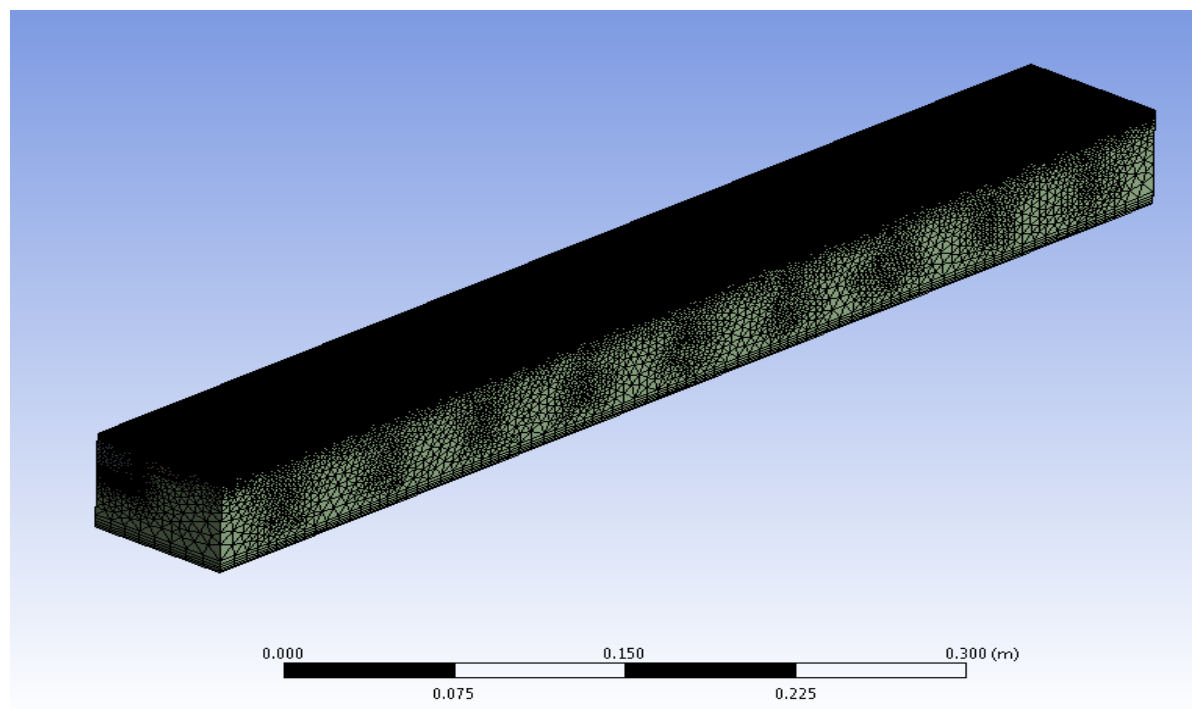

Figure 6. Mesh form of GDYF model

The granular duct takes more complicated form, so it has been taken half geometry to satisfy and support the mesh geometry, as shown in figure 7. 


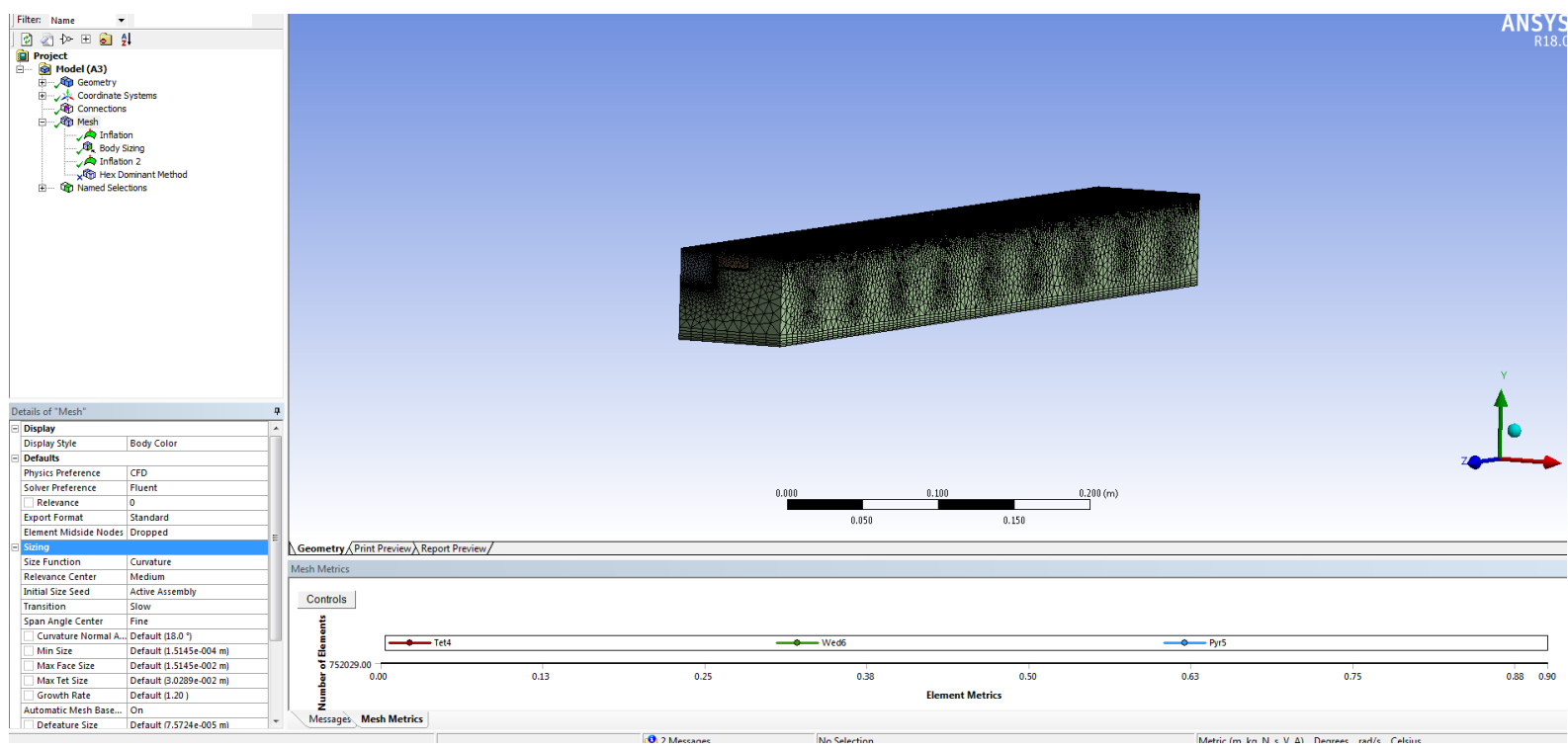

Figure 7. Mesh independent program steps for GDYF model

The adoption of the initial and boundary conditions in the simulation program (Ansys) includes heat flux, entry air velocity within the duct in addition to the thickness of the metal used, type and the method of insulation. Moreover, the flow velocity that taken for this research was 1,3 and $5 \mathrm{~m} / \mathrm{s}$, respectively.

a. Momentum equation

$$
\frac{\partial}{\partial \mathrm{t}}(\rho \mathrm{v})+\nabla \cdot(\rho \vec{v} \vec{v})=-\nabla \mathrm{p}+\nabla \cdot(\overline{\bar{\tau}})+\rho \vec{g}+\mathrm{S}
$$

b. Energy equation:

$$
\begin{gathered}
\rho \boldsymbol{C}_{\boldsymbol{p}}\left\lfloor\boldsymbol{U} \frac{\partial \mathrm{T}}{\partial \boldsymbol{X}}+\boldsymbol{V} \frac{\partial \mathrm{T}}{\partial \boldsymbol{y}}+\boldsymbol{W} \frac{\partial \mathrm{T}}{\partial \boldsymbol{z}}\right\rfloor=\left\lfloor\boldsymbol{U} \frac{\partial \mathrm{p}}{\partial \boldsymbol{X}}+\boldsymbol{V} \frac{\partial \mathrm{p}}{\partial \boldsymbol{y}}+\boldsymbol{W} \frac{\partial \mathrm{p}}{\partial \boldsymbol{z}}\right\rfloor+ \\
\boldsymbol{K} \nabla^{2} \boldsymbol{T}+\mu \Phi
\end{gathered}
$$

c. continuity equation

$$
\frac{\partial(\rho \mathrm{u})}{\partial \mathrm{X}}+\frac{\partial(\rho \mathrm{V})}{\partial \mathrm{Y}}+\frac{\partial(\rho \mathrm{W})}{\partial \mathrm{Z}}=0
$$

\section{Experimental Work}

A test rig was designed, fabricated and installed to validate the numerical model, as shown in figure 8 . In this study, the foam at the duct sides was tested with and without the presence of wax as an auxiliary factor for storage capacity and heat recovery.

\subsection{Producing Open- Cell Metal Foam Locally}

The first step in the experimental work was trying to manufacture the open cell -metal foam locally and produce metal foam blocks. But after three months of experimental tests in laboratory of Materials Department at the University of Technology, unfortunately, all attempts were unsuccessful to get an open-cell metal foam, as shown in figures 9 and 10

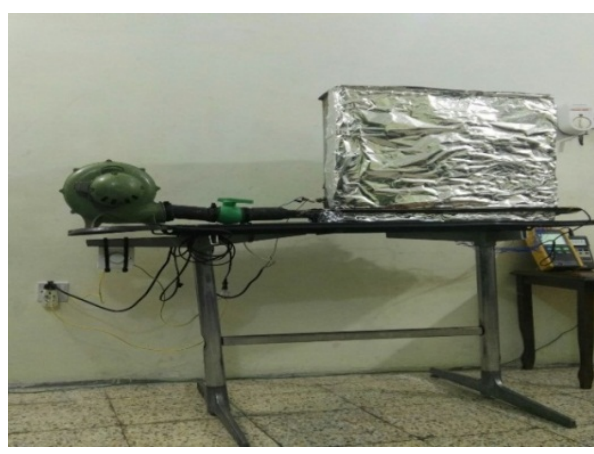

Figure 8. The test rig for the experimental facilities
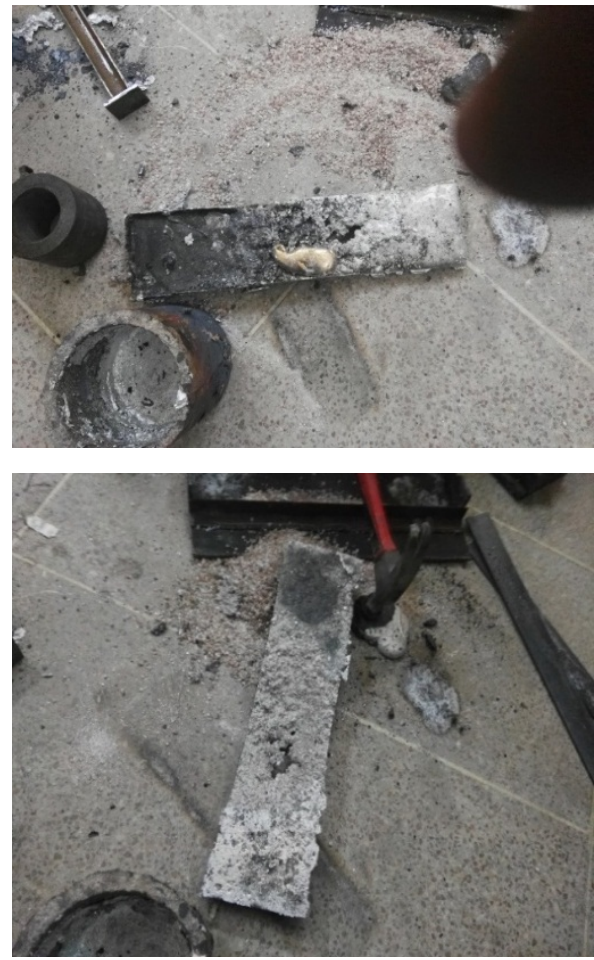

Figure 9. Manufacturing for metal foam 


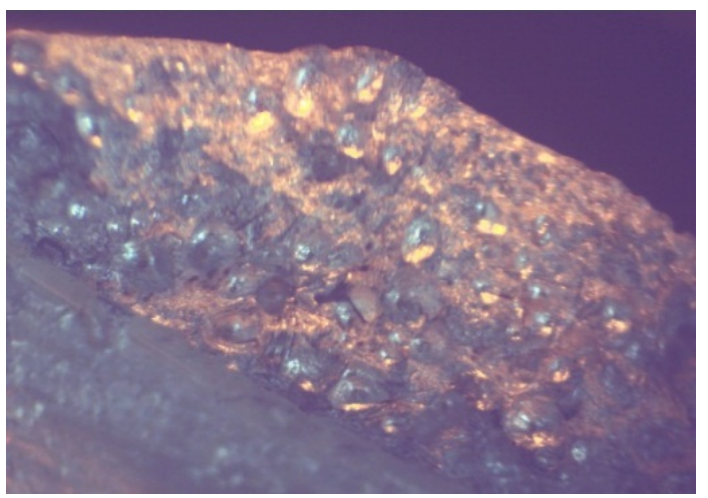

Figure 10. Microscopic view of the manufactured metal foam block

So, a commercial open- cell metal foam blocks were used in this work.

The heat source was supplied from the top cover of copper basin. The control electrical system (regulator) was used to manage the flow within the duct in both types smooth and dimple duct. The open cell metal foam was oriented horizontally in both side of the flow duct to maximize the utilization of thermal energy at an economical way, as shown in figure 11.

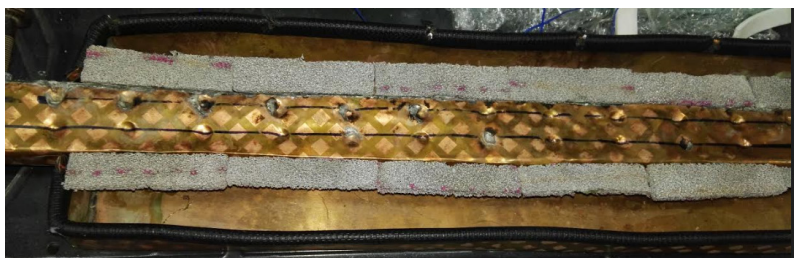

Figure 11. The duct with metal foam blocks

The copper basin is the main part for simulating the external wall cladding that proposed as a solar collector and storage unit, with a dimension $(150 \times 600 \times 60) \mathrm{mm}$. The basin plate has thickness $0.5 \mathrm{~mm}$. Open cell aluminum foam was used around the duct with a dimension of $(25 \times$ $60 \times 10) \mathrm{mm}$ for each piece, as shown in figure 12 . Two types of copper covers have were as a solar collector surface. The first one is a normal smooth horizontal plate with a thickness of $0.5 \mathrm{~mm}$. The second type is a horizontal plate with 18 pieces of copper cylinders that have been welded in the lower surface of cover. The cylinders diameters are $12 \mathrm{~mm}$ and $40 \mathrm{~mm}$ in length oriented vertically inside the duct in two lines $(9$ cylinders in each line), as shown in figure 13.

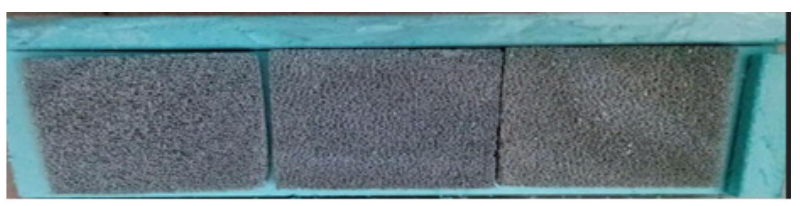

Figure 12. The shape of foam

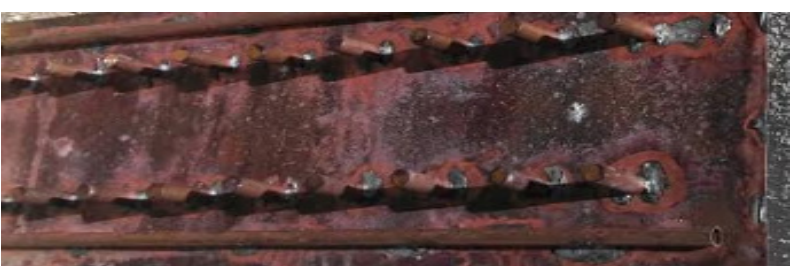

Figure 13. The cladding cover with copper cylinders

In this work, two types of air copper ducts were fabricated. The first duct has a smooth surface and the other has a granular dimpled surface with a radius of $10 \mathrm{~mm}$ diameter each with a total dimples of 80 half granular spheres, as shown in figure 14. The second is a smooth copper plate as shown in figure 15 .

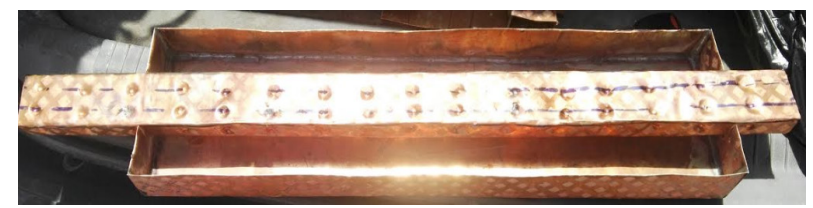

Figure 14. The granular duct surface

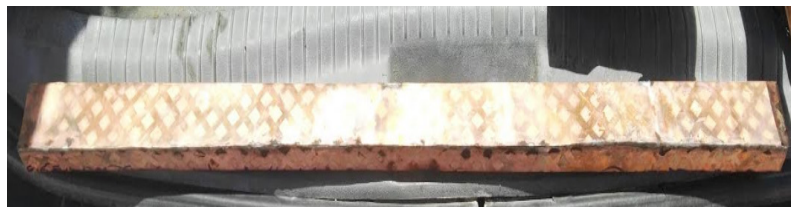

Figure 15. The smooth duct surface

An electrical heat source of $1200 \mathrm{~W}$ was insulated in a variable altitude stand and applied on the upper plate of duct and cover of basin. $600 \mathrm{~W}$ variable capacity air compressor capacity was used in the current work with rpm of $(0-1300)$. Thermocouples were fixed inside and outside the duct. For the outside duct, six thermocouples were fixed along the basin line plane between the edge of the foam and copper cylinders with equal spaces between them (60 mm gaps). In addition, other six thermocouples were fixed along the fluid flow duct in symmetrical spaces with the previous six channels.

\section{Results and Discussion}

Figures (16-18) showing a validation between experimental and numerical results for SDSC- base model. It is found that when increase experimental or CFD air velocity from 1 to $3 \mathrm{~m} / \mathrm{s}$, the air temperature decreased $25 \%$. While, when increasing the velocity of air from 3 to $5 \mathrm{~m} / \mathrm{s}$, the air temperature decreased $14 \%$. 


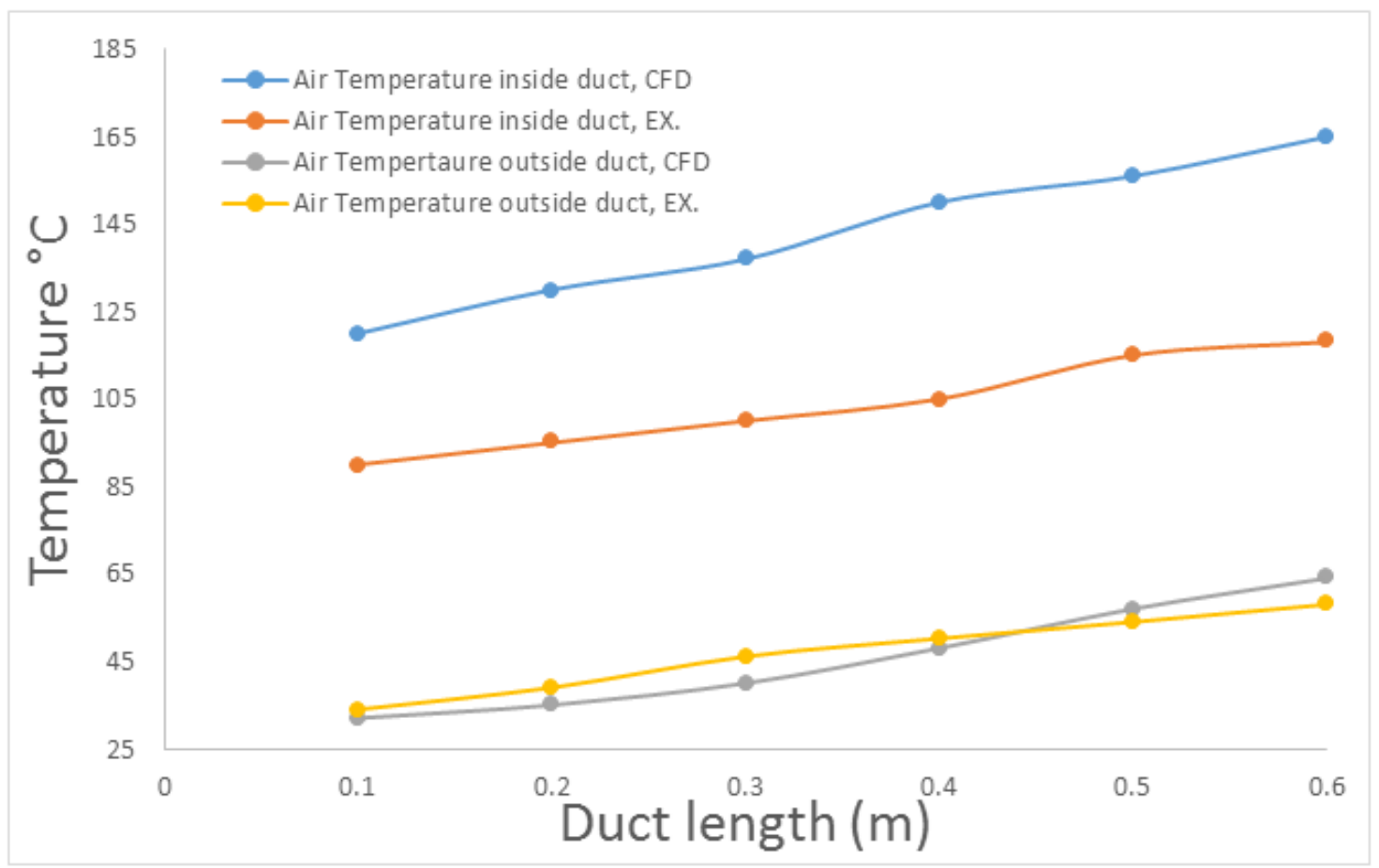

Figure 16. Validation of the experimental results with CFD results for the temperature of the working fluid at velocity of $1 \mathrm{~m} / \mathrm{s}$

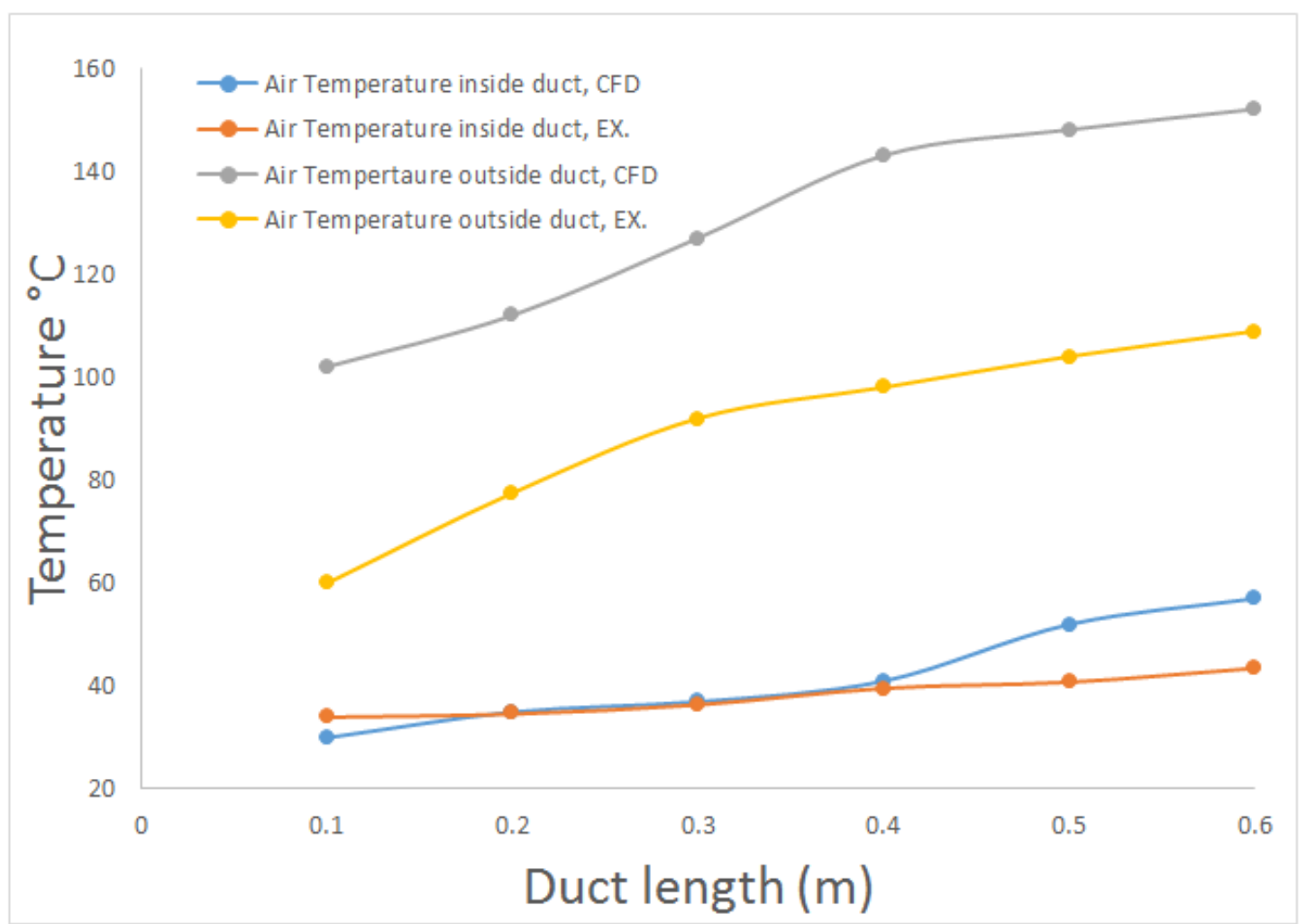

Figure 17. Validation of the experimental results with CFD results for the temperature of the working fluid at velocity of $3 \mathrm{~m} / \mathrm{s}$ 


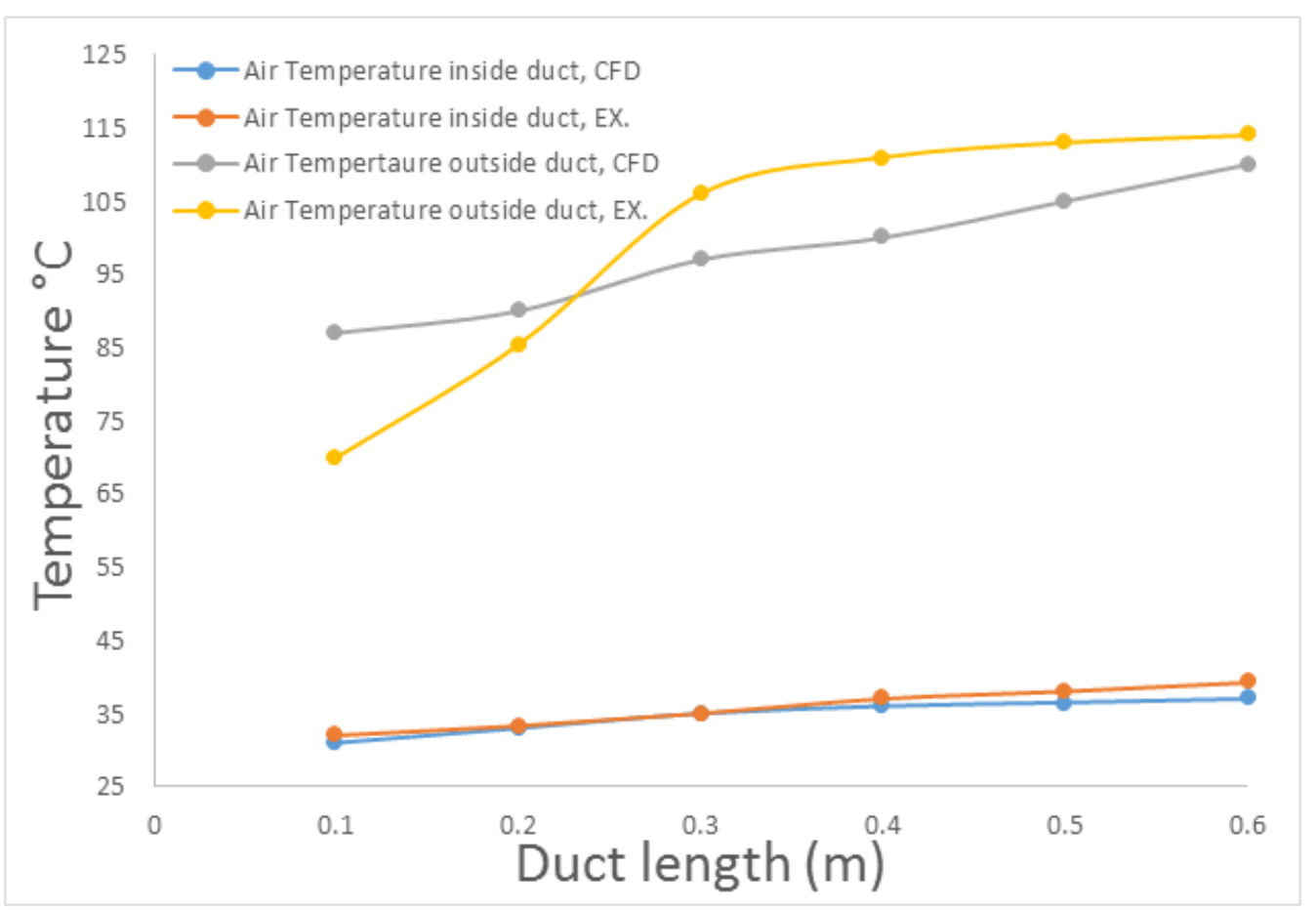

Figure 18. Validation of the experimental results with CFD results for the temperature of the working fluid at velocity of $5 \mathrm{~m} / \mathrm{s}$

Figures 19, 20 and 21 illustrate the air temperature distribution for SDYF model. It can be concluded that there is an enhancement in the heat transfer when using both foam and cylinders. The percentage enhancement in the temperature of air between this case and SDSC model at the velocities 1,3 and $5 \mathrm{~m} / \mathrm{s}$ is $8,8.4$ and $15.8 \%$, respectively; from the results it is clear the effect of cylinders inside the storage area on the heat gain.

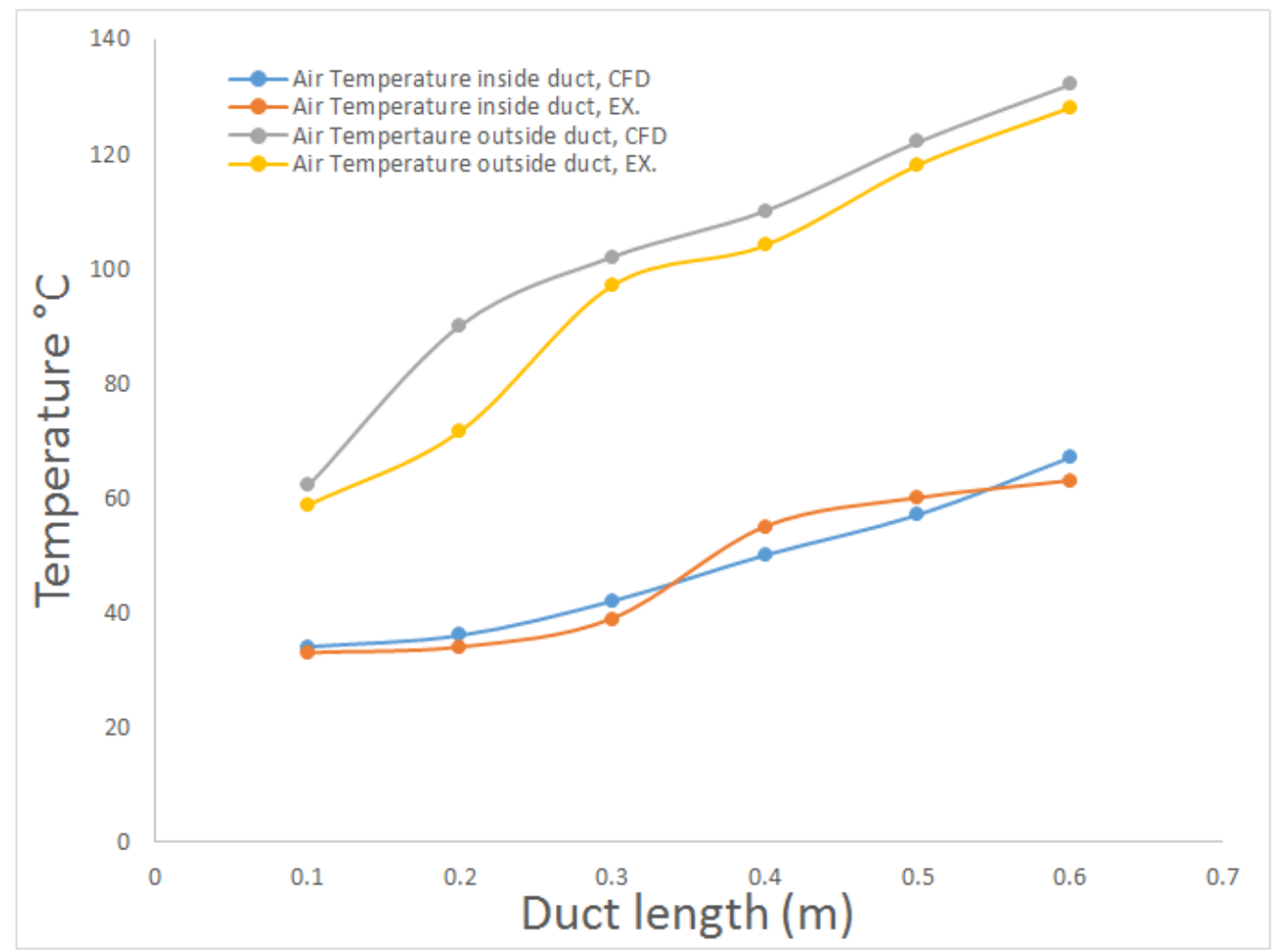

Figure 19. Temperature distribution of the air along the duct for SDYF at an air velocity of $1 \mathrm{~m} / \mathrm{s}$ 


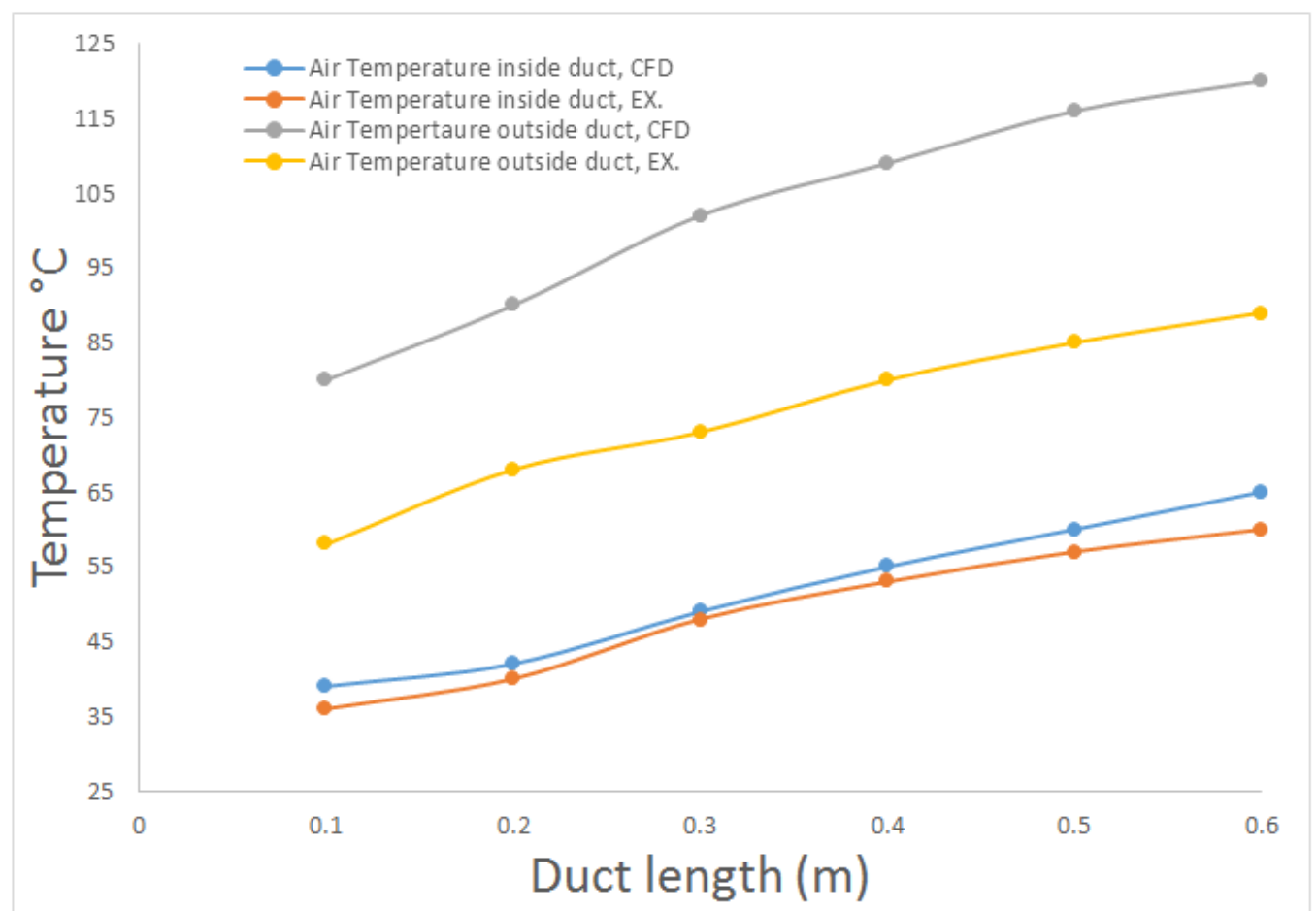

Figure 20. Temperature distribution of the air along the duct for SDYF at an air velocity of $3 \mathrm{~m} / \mathrm{s}$

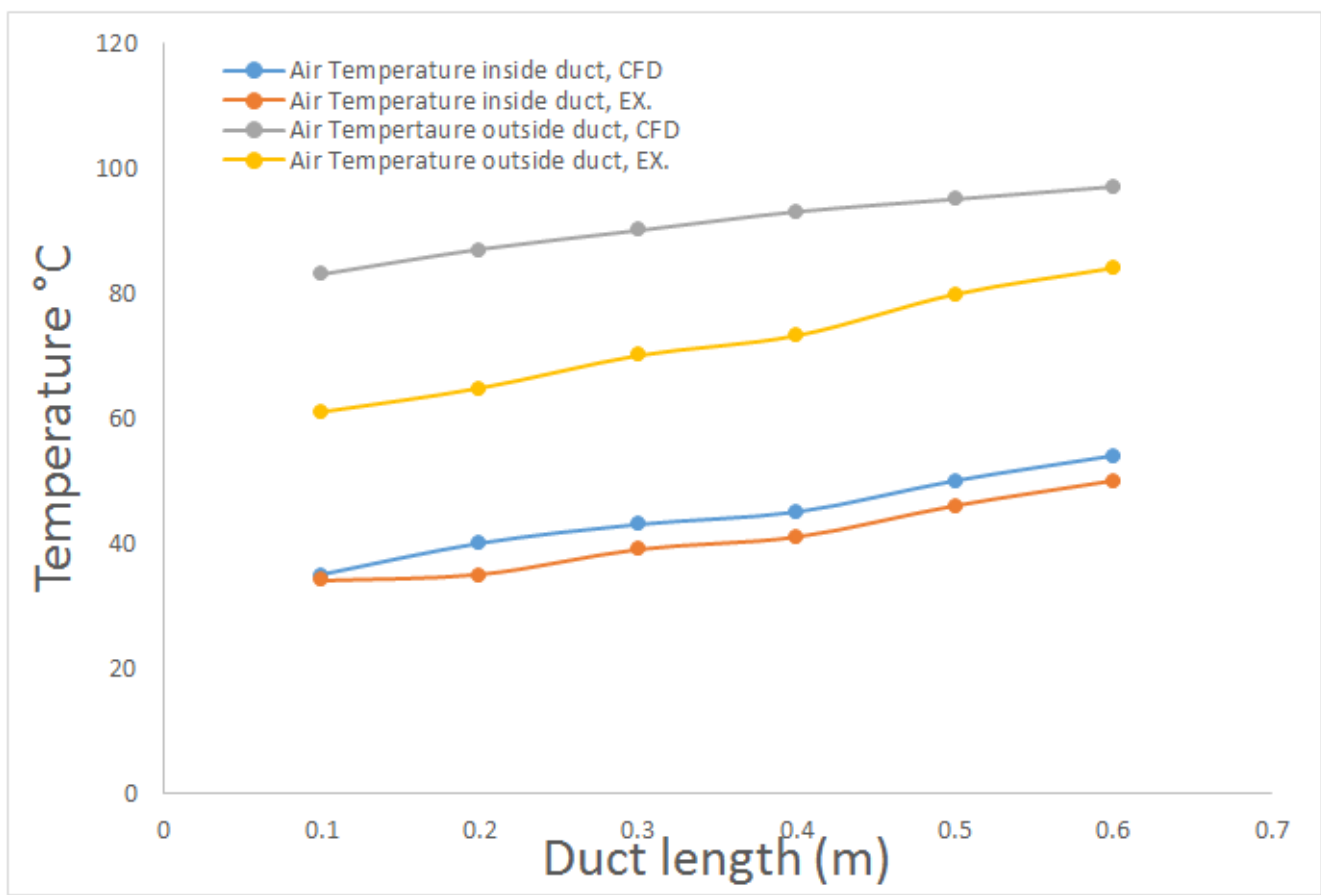

Figure 21. Temperature distribution of air along the duct for SDYF at an air velocity of $5 \mathrm{~m} / \mathrm{s}$

For granular duct with cylinders and foam (GDYF Model), it is found that the percentage of enhancement in the temperature of air between this case and SDSC model at the velocities 1,3 and $5 \mathrm{~m} / \mathrm{s}$ is $28.8,34$ and $35.7 \%$, respectively. The distribution of air temperature at velocity of $1 \mathrm{~m} / \mathrm{s}$ is elucidated in figure 22 , while at $3 \mathrm{~m} / \mathrm{s}$ and $5 \mathrm{~m} / \mathrm{s}$, it is evinced in the figures 23 and 24, respectively; the results show the major effect of heat gain by increase the duct area. 


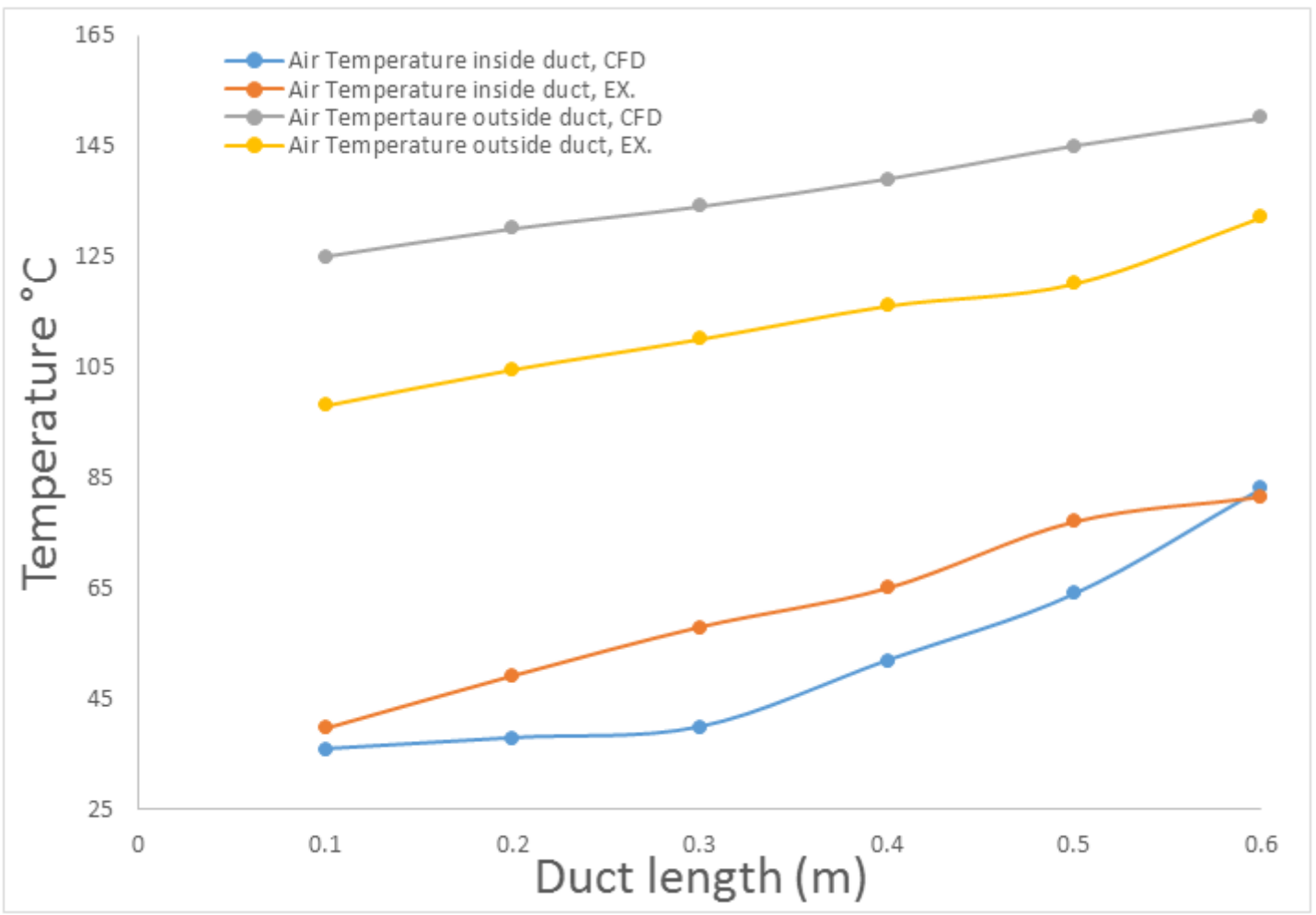

Figure 22. Temperature distribution of air along the duct for GDYF at an air velocity of $1 \mathrm{~m} / \mathrm{s}$

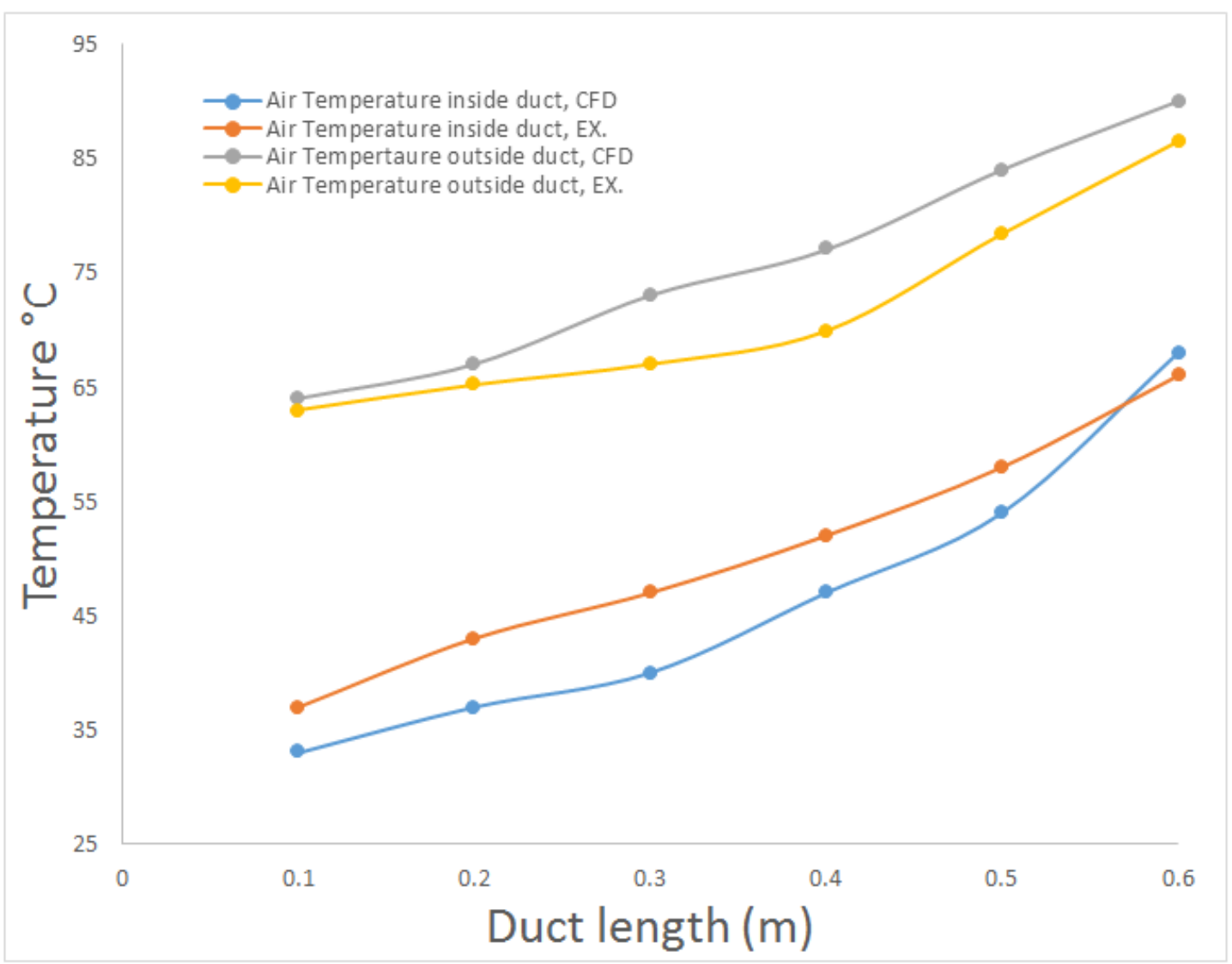

Figure 23. Temperature distribution of air along the duct for GDYF at an air velocity about of $3 \mathrm{~m} / \mathrm{s}$ 


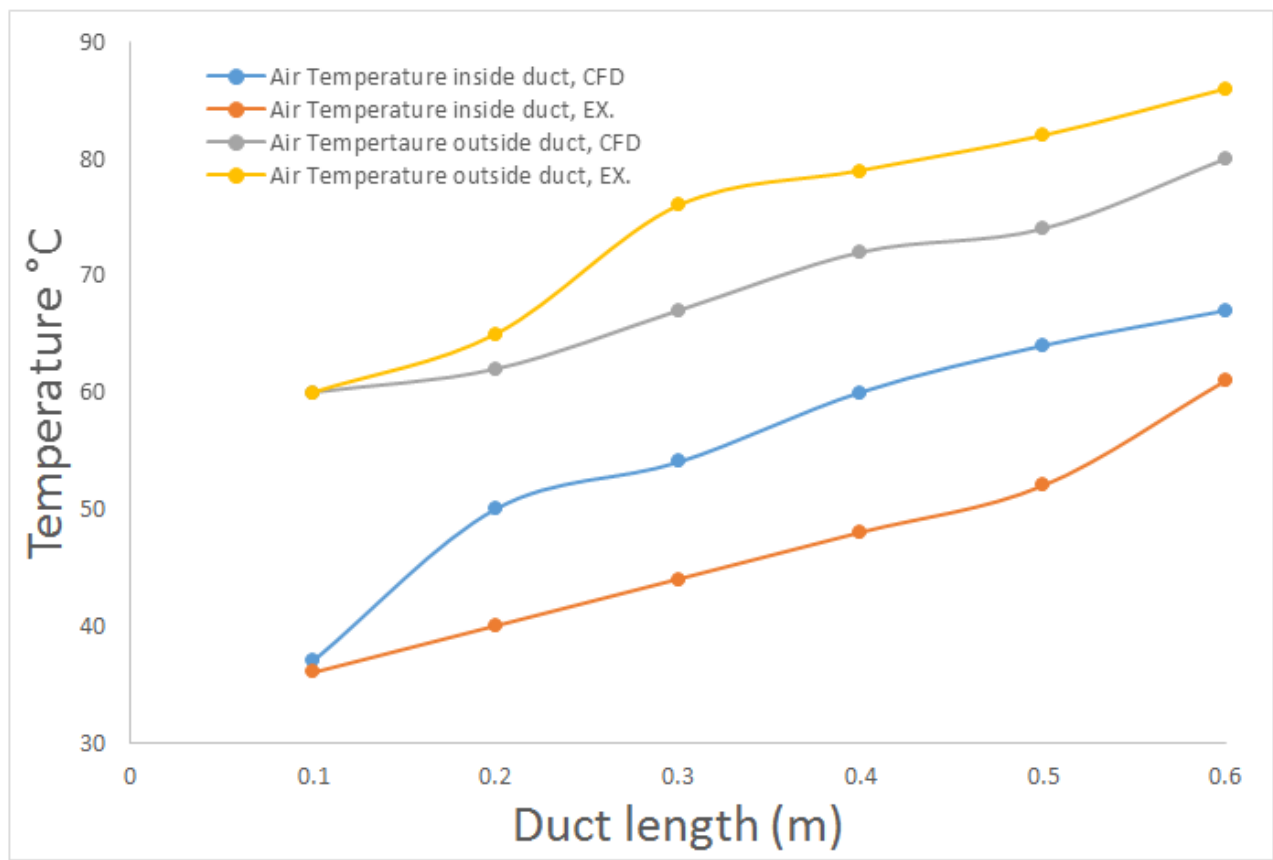

Figure 24. Temperature distribution of air along the duct for GDYF at an air velocity about of $5 \mathrm{~m} / \mathrm{s}$

\subsection{GDYFW Model}

In order to investigate the effect of adding PCM on the thermal performance of the system, paraffin wax was added around the duct (GDYFW model). It is found that there is an enhancement in the heat transfer after a long time, but after a short time, it's clear that there is a decrease in the thermal gain rate. The decrease in the temperature of air between this case and GDYF case at the velocities 1,3 and $5 \mathrm{~m} / \mathrm{s}$ is 7,13 and $13{ }^{\circ} \mathrm{C}$, respectively, as shown in figures 25,26 and 27.

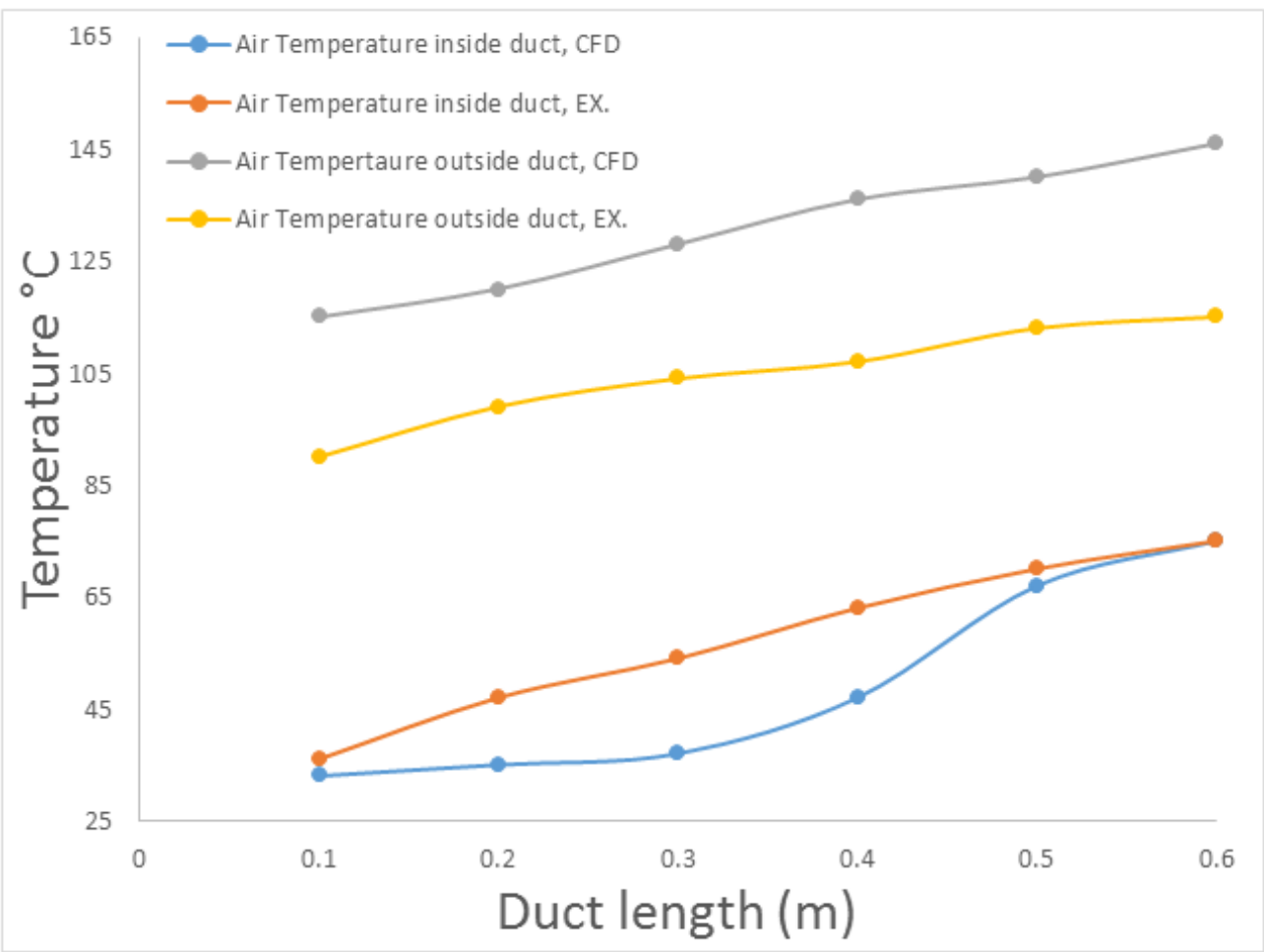

Figure 25. The temperature distribution of air along the duct for GDYFW model at an air velocity of $1 \mathrm{~m} / \mathrm{s}$ 


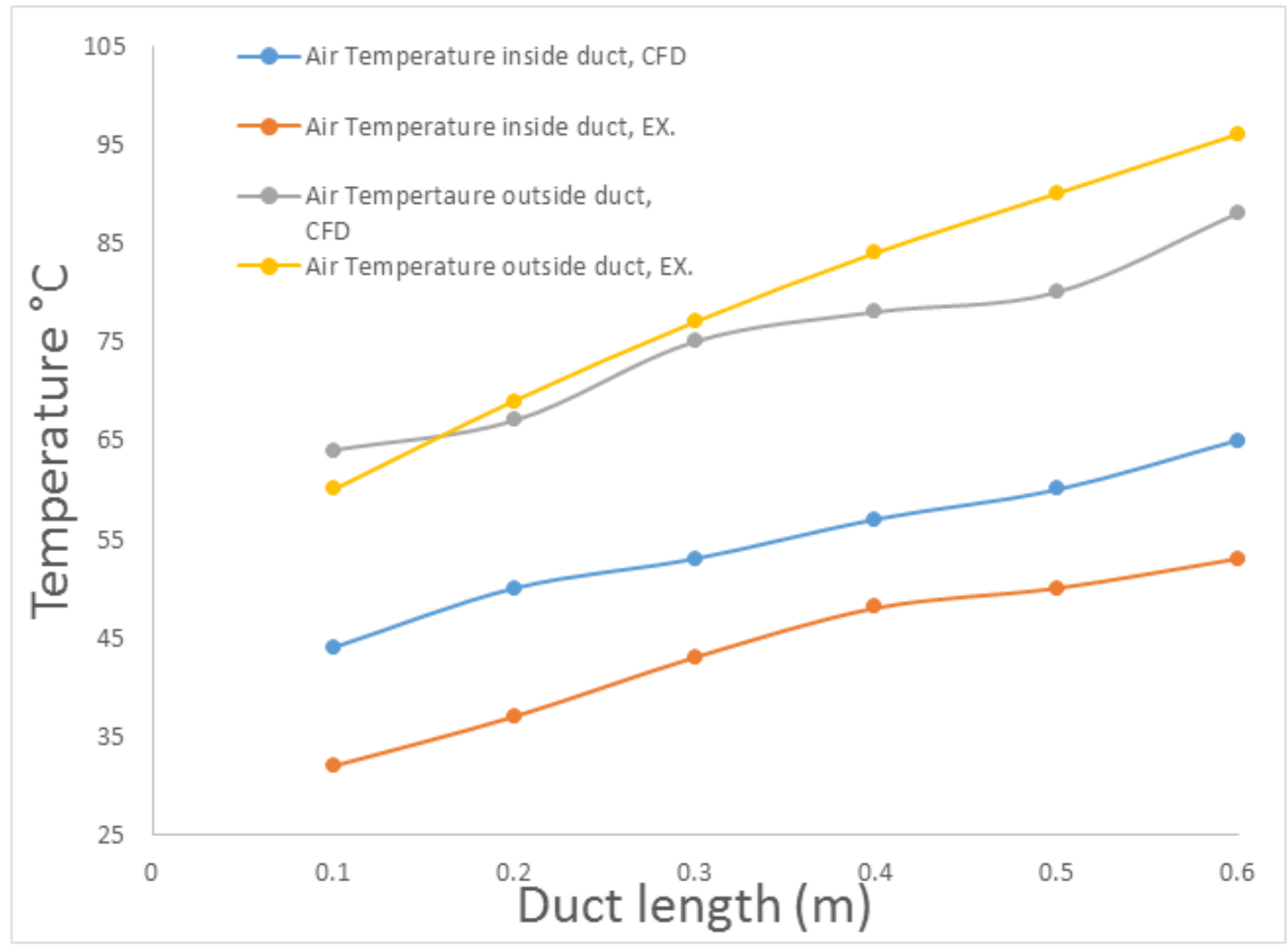

Figure 26. Temperature distribution of air along the duct for GDYFW model at an air velocity of $3 \mathrm{~m} / \mathrm{s}$

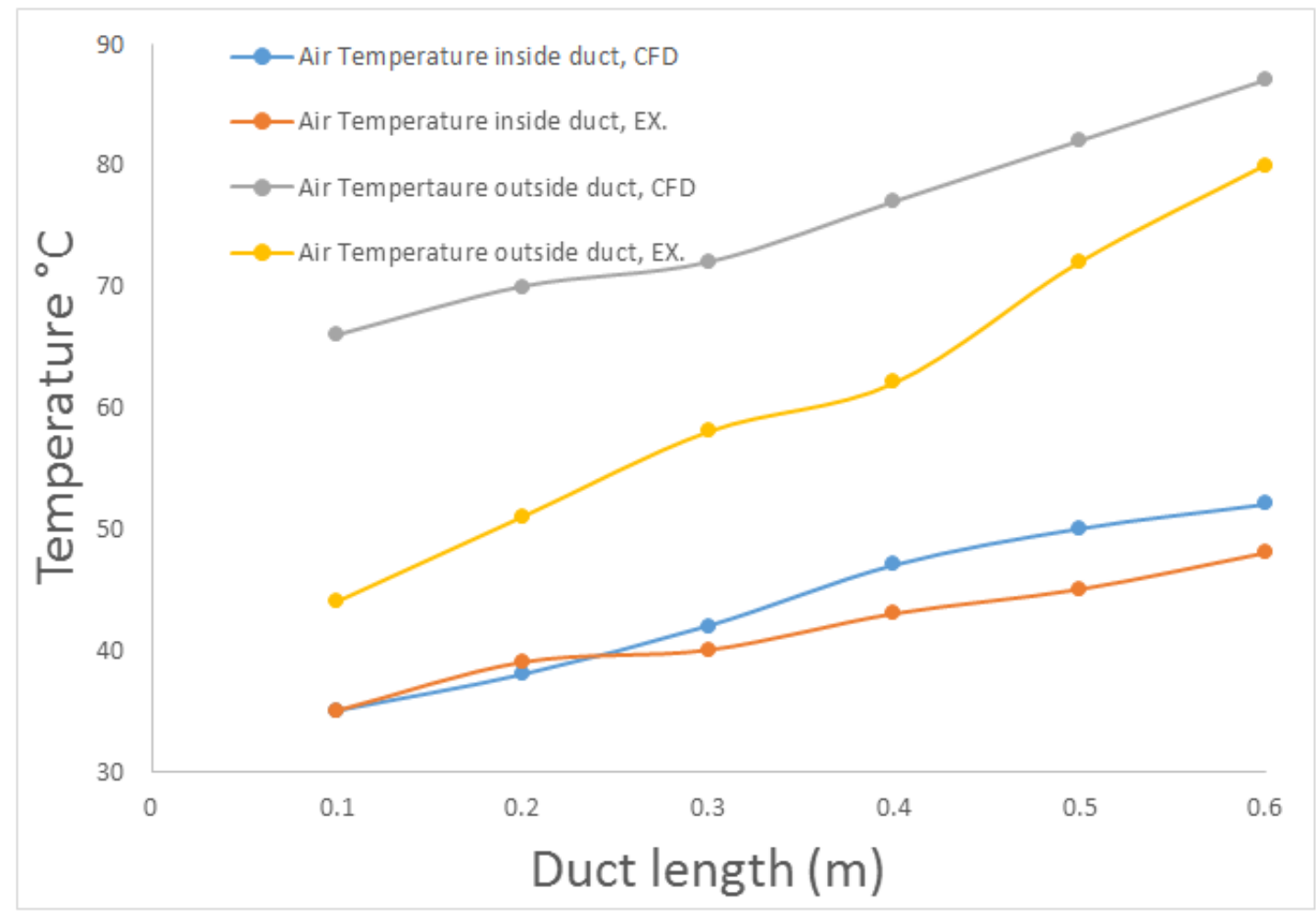

Figure 27. Temperature distribution of air along the duct for GDYFW model at an air velocity of $5 \mathrm{~m} / \mathrm{s}$ 
From the experimental results, a new predicted correlation equation for Nusselt number was found by using multiple regression analysis, the following equation has been developed in order to calculate the Nusselt number for various Reynolds numbers for (GDYF) model.

$$
\mathrm{Nu}=0.574 \times 10^{-1} R e^{0.825}
$$

Beyond conducting the parameters, the effective study via utilizing the suggested FEM model, the gained otcomes have been categorized in accordance with the level of their effectiveness (by putting all parameters that have effect on the temperature supply as variables and arrangement as an equation of the temperature supply as a function of these variables). The above categorized has been used for getting a dimensionless equation through utilizing numerous forms (making both sides of equation is equilibrium regarding the units) for the dependent and independent variables. To compute the factors and indexes for every term in the equation, various mathematical procedures that are adopted in the regression have been employed, like, line, power, etc. Nevertheless, it was obtained that is the highly precise way as scored the highest value in the case among the others. Microsoft Excel was employed as a tool for conducting the regression.

\section{Conclusions}

In the present work, building a wall cladding system has been developed and tested experimentally and numerically. The thermal performance of this system has been improved through investigating and testing several enhancement methods. According to the obtained results, several significant conclusions can be summarized as follows;

1. The added open - cell metal foam to smooth duct (SDYF model) has been found to improve the thermal performance by about of $8 \%$ for the air velocity of 1 $\mathrm{m} / \mathrm{s}$, and this improvement increased with the air velocity of 3 and $5 \mathrm{~m} / \mathrm{s}$ to about 8.4 and $15.8 \%$, respectively.

2. The use of metal foam with granular duct (GDYF model) has been found to improve the thermal gain where the improvement rate is about $29 \%$ for air velocity of $1 \mathrm{~m} / \mathrm{s}$, and for air velocity of 3 and $5 \mathrm{~m} / \mathrm{s}$, it is 34 and $35.7 \%$, respectively.

3. The effect of using double effect of both metal foam and PCM have been found not significant for improving the transient temperature response inside the duct. In fact, adding PCM to the metal foam is found to reduce the thermal gain by approximately 9 to $11 \%$ with respect to the metal foam alone.

4. A new correlation equation to estimate the Nusselt number has been developed for the best thermal response model (GDYF model).

\section{Acknowledgements}

This research was supported by [Dr Basim Freegah] from [Almustansirya University, College of Engineering] who gave the access to the laboratory and research facilities. Without his precious support, it would not be possible to conduct this research.

\section{Abbreviations}

SDSC: Smooth duct smooth cover.

SDYF: Smooth duct cover cylinders with foam.

GDYF: Granular duct cover cylinders with foam.

GDYFW: Granular duct cover cylinders with foam and wax.

\section{REFERENCES}

[1] M. F. Ashby, A. G. Evans, N. A. Fleck, L. J. Gibson, J. W. Hutchinson and H. N. G. Wadley. (2001). "Metal foams: a design guide." Applied Mechanics Reviews 54: B105.

[2] Salam, R. (2011). Simulation and optimization of solar thermal system integrated with PCM thermal energy storage for seawater desalination, Cairo University.

[3] Nihad Dukhan, Ozer Bag c1 and Mustafa Ozdemir. (2015). "Thermal development in open-cell metal foam: an experiment with constant wall heat flux," International Journal of Heat and Mass Transfer 85: 852-859.

[4] Nawaz, K. (2014). Aerogel coated metal foams for dehumidification applications, University of Illinois at Urbana-Champaign.

[5] Beibei Shen, Hongbin Yan, Bengt Sunden, Hongqian Xue, and Gongnan Xie. (2017). "Forced convection and heat transfer of water-cooled micro channel heat sinks with various structured metal foams." International Journal of Heat and Mass Transfer 113: 1043-1053.

[6] M. M. Alkilani, K. Sopian, Sohif Mat and M. A. Alghoul. (2009). "Output air temperature prediction in a solar air heater integrated with phase change material." European Journal of Scientific Research 27(3): 334-341.

[7] Du, Y. and Y. Ding (2016). "Towards improving charge/discharge rate of latent heat thermal energy storage (LHTES) by embedding metal foams in phase change materials (PCMs)." Chemical Engineering and Processing: Process Intensification 108: 181-188. 